\title{
DESENVOLVIMENTO DE MAPAS COM PERSPECTIVA TRIDIMENSIONAL: CONTRIBUIÇÕES AO ENSINO DE GEOMORFOLOGIA
}

\author{
Rafael Rodrigues Brizzi ${ }^{(a)}$, Andréa Paula de Souza ${ }^{(b)}$, Alexander Josef Sá Tobias da Costa ${ }^{(c)}$, \\ Kelly Souza Costa ${ }^{(d)}$
}

(a) Instituto Federal do Rio de Janeiro. Email: rrbrizzi@gmail.com

(b) Departamento de Geografia/Faculdade de Educação da Baixada Fluminense, Universidade do Estado do Rio de Janeiro. Email: andreaps_uerj.febf@yahoo.com.br

(c) Departamento de Geografia/Instituto de Geografia, Universidade do Estado do Rio de Janeiro Email: ajcostageo@gmail.com

(d) Mestranda do programa de Pós Graduação de ensino em Educação Básica da Universidade do Estado do Rio de Janeiro.

\section{Eixo: GEOGRAFIA FÍSICA: CURRÍCULO, FORMAÇÃO E PRÁTICAS DE ENSINO}

\begin{abstract}
RESUMO: O avanço da tecnologia tem aumentado o interesse do discente para a compreensão do espaço geográfico, pois softwares como o Google Earth e QGIS facilitam essa aproximação, tornando o ensino de geografia física menos abstrato, mais lúdico e atraente. Logo, tem-se como proposta a criação e a aplicação de mapas com perspectiva 3D nas aulas de geomorfologia, pois estes se mostram como facilitadores de delimitação/interpretação de bacias hidrográficas e seus componentes em estudos que envolvem impactos ambientais, e possibilitam a interdisciplinaridade, que comunga para uma melhor interpretação do espaço geográfico. A metodologia usada para este trabalho contou com a utilização de softwares como o ERDAS, Global Mapper e ArcGis. Ressalta-se que o método se baseia em princípios aerofotogramétricos largamente abordados na literatura, sendo fundamental sua compreensão para a utilização do produto final em sala de aula, onde o mesmo mostrou-se eficiente e facilitador dos conceitos geomorfológicos e de suas aplicações no ensino básico.
\end{abstract}

Palavras-Chave: Anaglifos, ensino de geomorfologia, geografia física

\section{Geomorfologia e o Uso de Anaglifos no Ensino}

Compreender a relação homem-natureza é uma abordagem cada vez mais necessária, pois no mundo globalizado em que vivemos tanto os educandos como os educadores têm presenciado novos desafios nas diferentes áreas de conhecimento, assim como nos diferentes níveis de educação. Ressalta-se que neste viés a geografia tem um papel relevante, pois fomenta a formação para a necessidade de compreensão e intervenção na realidade.

A geomorfologia é uma das primordiais áreas de conhecimento da geografia, pois estuda e compreende o relevo no stricto sensu, mas também para a reprodução da sociedade e de suas atividades, desde exploração de recursos naturais, as ocupações urbanas, até os processos erosivos, enchentes, movimentos de massa, entre outros (Castro \& Silva, 2014). Isto é, o conjunto de conhecimento da geomorfologia se torna um instrumento da geografia, permitindo a compreensão de como o relevo está associado às mais 
diversas atividades humanas (Bertolini \& Valadão, 2009). Entretanto, é notório que os discentes, do ensino superior, futuros professores, têm grandes dificuldades de se apropriar dos conhecimentos geomorfológicos e relacioná-los à geografia escolar, uma vez que essa é de cunho predominantemente crítica (Venturi, 2008). Logo, conforme Armstrong (2008) o desenvolvimento de metodologias que possibilitem o conhecimento científico é fundamental, pois "cabe ao professor o papel de estabelecer critérios e estratégias pedagógicas, como forma de orientar [...] fatos ou fenômenos estudados em sala de aula". Nesse sentido o educador deve integrar a tecnologia à educação escolar elevando o nível de qualidade do ensino.

Embora o uso de imagens de satélite e fotos aéreas não promova a integração do discente in loco com a natureza, essas proporcionam uma visão de conjunto, revelam aspectos ocultos, que permitem a compreensão de conceitos e fenômenos como: bacias hidrográficas, divisores topográficos, como também o crescimento de áreas urbanas e desmatamentos (Venturi, 2008). Um exemplo é a técnica do anaglifo, pois é uma das inúmeras técnicas usadas para a observação em três dimensões (3D) de duas fotografias (aéreas ou terrestres) ou de dois desenhos que possuem recobrimento comum, que apesar de ser uma técnica antiga vem sendo crescente e motivado principalmente pelos avanços de hardware e software (Disperati \& Schuler, 2010). Passou a ser difundida nos últimos anos principalmente nos cinemas, mas que também vem alcançando o espaço educacional, com grande potencialidade de uso. Desta forma, propõe-se o uso de mapas anaglifos, como recurso didático, na construção do conhecimento geomorfológico para os discentes do curso de licenciatura em geografia.

\section{Metodologia}

A metodologia usada na geração dos anaglifos contou com a utilização de softwares privados como o ERDAS-Image, Global Mapper 15 e ArcGis 10.2.2, Todos licenciados para o IBGE/Parada de Lucas/RJ. Foi necessária a utilização de arquivos no formato raster e vetorial, como o Modelo Digital de Terreno (MDT), Ortofotos (ambos compatíveis com a escala de 1.25.000, disponível no site do IBGE), rede de drenagens e delimitação de bacias hidrográficas no formato shapefile, respectivamente. Após a sobreposição de camadas no software global mapper, foi exportada uma imagem final no formato "img". Antes de gerar a imagem com perspectiva tridimensional, é preciso mosaicar e exportar o MDT na extensão "X.Y.Z", sendo necessário trocar para a extensão "DAT" (extensão reconhecida pelo ERDAS ambos arquivos de leitura). Posteriormente é inserido o MDT e a Ortofoto (ambos no formato "img") no software ERDAS-Image, que gera a imagem no formato tridimensional. Antes da fusão das imagens é necessário escolher o exagero vertical do modelo (ou seja, exagerar o relevo para melhor visualização das formas geomorfológicas) e a composição de cores para posterior visualização com o óculo anaglífico nas 
cores vermelho (esquerdo) e azul (direito). Por fim, é gerado um layout final no software ArcGis 10.2.2 que irá caracterizar o mapa em 3D na escala desejada.

Ressalta-se que o método baseia-se em princípios aerofotogramétricos que dão base para o entendimento da paralaxe estereoscópica, onde através sobreposição de duas imagens sob perspectivas ortogonais diferentes é possível gerar uma imagem tridimensional (Disperati \& Schuler, 2010). Existem outras formas de visualização do espaço-objeto de forma tridimensional, entretanto, foram utilizados os óculos anaglíficos que representam, junto com as cores correspondentes das duas imagens (vermelho e azul), o plano de vôo aerofotogramétrico. Ou seja, a sobreposição das imagens em perspectivas ortogonais diferentes sobre um mesmo objeto mapeado.

Os mapas anaglifos foram utilizados com a turma do terceiro período (2016.1) do curso de licenciatura em Geografia, da Faculdade de Educação da Baixada Fluminense/UERJ, na disciplina de Processos Geomorfológicos I. O programa da disciplina trabalha as perspectiva geométrica/morfométrica das formas de relevo, levando ao aluno, por exemplo, a compreensão da bacia hidrográfica, da visão em planta; visão em perfil; formas básicas de encostas, topos, vales; elementos geométricos e geomórficos de cabeceiras de drenagem; morfometria de cabeceiras. Para tal foram utilizados os mapas anaglifos e também cartas topográficas, que após as análises geomorfológicas os alunos as relacionaram com diferentes possibilidades de uso do solo e da água na bacia hidrográfica. Além disso, também foi pedido aos alunos que se fizessem o levantamento de conceitos geomorfológicos nos livros didáticos do $2^{\circ}$ ciclo do ensino fundamental, com o propósito de despertar o olhar docente para o uso de uma das suas ferramentas didáticas.

\section{Resultados}

Conforme exposto anteriormente o trabalho aqui propõe o uso de mapas anaglifos, como material didático, na construção do conhecimento geomorfológico para discentes do curso de licenciatura em geografia, uma vez que os mesmos sentem grande dificuldade desde a delimitação da bacia hidrográfica até a visão em perfil. Desta forma, foram produzidos anaglifos de diversas áreas e municípios, entretanto nesse trabalho será mostrado apenas da porção norte do Município de Duque de Caxias (Figura 1).

Os mapas anaglifos, a partir da visão 3D auxiliam na visualização e compreensão direta dos divisores topográficos (Figura 1), contrapondo a grande dificuldade mesmo quando da visão em perfil da bacia hidrográfica, trabalhada na carta topográfica. Outra questão sinalizada pelos discentes foi à visão de "conjunto" que passaram a ter com os anaglifos, pois na carta tinham visão da superfície de forma descontínua. Detectaram também a ocupação do fundo do vale, em algumas áreas, subindo as encostas, o que não detectavam nas cartas topográficas. Ao fazer correlação de quais e como os conteúdos de 


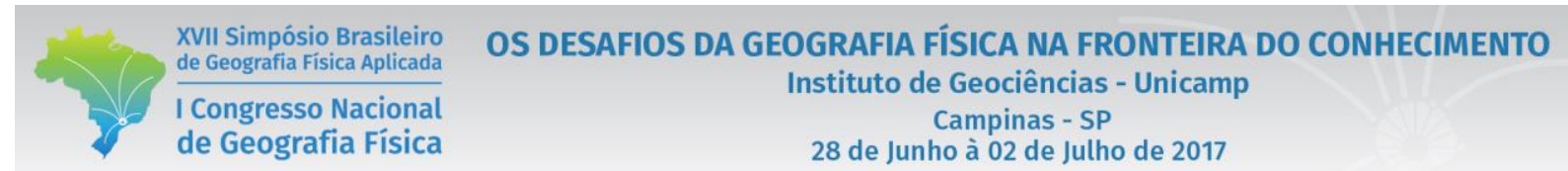

geomorfologia são abordados nos livros didáticos, observaram que estes apresentam imagens de satélite para exemplificarem diversos conteúdos curriculares, mas acabam por explorar pouco este recurso didático, principalmente, quando relacionado aos conhecimentos geomorfológicos, o que é ressaltado no trabalho de Bertolini e Valadão (2009).

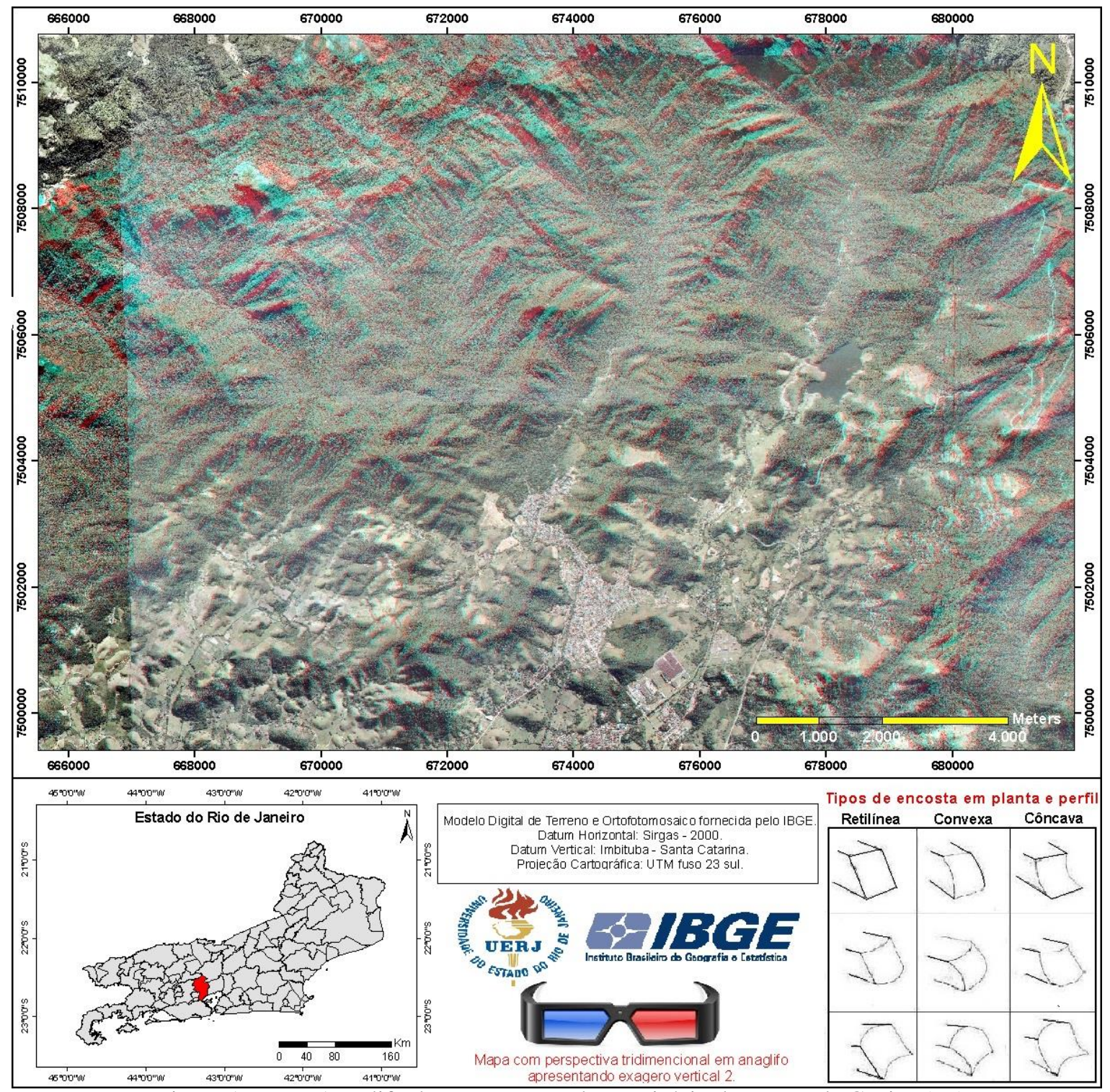

Figura 1. Mapa Anaglifo da porção norte do Município de Duque de Caxias (RJ).

Nota-se que alguns alunos têm certa dificuldade em visualizar as imagens tridimensionais com os óculos 3D, talvez seja por falta de prática na utilização dessa técnica, entretanto, a grande maioria dos discentes da disciplina de geomorfologia interagira muito bem com a técnica em questão e expuseram que a metodologia aplicada em muito auxiliou na superação de dificuldades presentes no processo de ensino aprendizagem, principalmente na compreensão do conceito de bacias hidrográficas, o mesmo foi 
encontrado no trabalho de PIRES et. al. (2016). Outros aspectos facilitados foram relevo, vegetação, hidrografia, densidade populacional, ocupação urbana.

\section{Considerações}

Pode-se dizer que a utilização de geotecnologias, principalmente com o uso de técnica de mapas anaglífos (imagens tridimensionais) quando bem planejadas como recurso didático para os discentes de licenciatura e futuros professores, além de serem recursos pedagógicos desejados, também são bem aceitos na compreensão de conceitos geomorfológicos. Em suma, o uso de geotecnologias como mapas anaglifos foi um recurso bastante benéfico no ensino de geomorfologia, assim como no fazer compreender dos discentes de que formas os mapas podem ser utilizados em aulas do ensino fundamental e médio, pois trazem a possibilidade da abordagem interdisciplinar.

\section{Bibliografia}

ARMSTRONG, D.L.P. Fundamentos Filosóficos do ensino de ciências naturais. Curitiba: IBPEX, 2008.

BERTOLINI W. Z.; VALADÃO R. C. A abordagem do relevo pela geografia: uma análise a partir dos livros didáticos, Campinas, Terræ Didatica, 5(1):27-41. 2009.

CASTRO, C. M.; SILVA, T.M. Apropriação do relevo e paisagens tecnogênicas: discussões acerca do ensino da geomorfologia com base em exemplos cariocas e fluminenses, Campinas, TERRÆ DIDATICA 10-2:81-90. 2014.

DISPERATI, A.A.; SCHULER, C.A.B. Anaglifos digitais e sua aplicação na fotointerpretação temática. $1^{\mathrm{a}}$ ed., Guarapuava: Unicentro, 2010.

PIRES, T. B.; PEREIRA, T.H.A.A.; PIPITONE M.A. P. O Uso do Google Earth e a apresentação de imagens tridimensionais como ferramentas complementares para a educação ambiental, Fortaleza, Geosaberes, v. 7, n. 13, p. 112-122, jul. / dez. 2016.

VENTURI, L. A. B. V. Ensaio geográfico. São Paulo: Humanitas, 2008.

\section{Agradecimentos}

Agradecemos ao Instituto Brasileiro de Geografia e Estatística (IBGE- Parada de Lucas) pela possibilidade de desenvolvimento do material em suas instalações com disponibilidade de softwares e ploters. Ao NIESBF/FEBF/UERJ que cedeu espaço para uso dos anaglifos com alunos. 